\title{
A USEFUL TYPE OF AIR THERMOMETER.
}

By E. J. RendtorfF,

Lake Forest Academy, Lake Forest, Ill.

I wish to present a form of air thermometer that I have found extremely useful in qualitative class demonstrations of some of the phenomena of heat, of light and of electricity. It has the virtue of being inexpensive, compact and universal in its uses, being adapted to either bench or projection purposes.

Most science teachers in secondary schools are given so little time to prepare experiments for class demonstration that the tendency is to neglect them, unless they are of such character that the apparatus can be assembled in class, with little loss of time. It is also frequently difficult to procure a sufficiently extended set of apparatus for this purpose and the average teacher is fortunate who manages to equip his regular

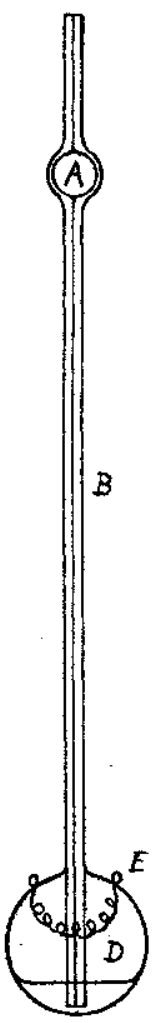
laboratory with the apparatus needed for the fundamental work. It is therefore essential that the apparatus for class demonstration be universal in their application and not intended for one demonstration only. This property the air thermometer herein described most certainly possesses.

The apparatus consists of a bulb $\mathrm{D}$, having a diameter of about $5 \mathrm{~cm}$., to which is sealed a tube $B$, about $25 \mathrm{~cm}$. long and of $I \mathrm{~mm}$. internal diameter, reaching almost to the bottom of the bulb. Near the top of the tube is a small bulb, A, to prevent an overflow of the colored liquid (kerosene) that partially fills D. A small coil, $\mathrm{E}$, of $\mathrm{Pt}$ wire is sealed in the lower bulb and makes the use of the apparatus more extended, though it is not essential for all the demonstrations described. below.

I will outline a few experiments in heat, light and electricity for which the apparatus is adapted. Many others will suggest themselves to every ingenious teacher.

I. Expansion of gases due to heat. Hold the butb in the hand or over any source of heat.

2. Heat produced by friction. Rub the bulb. vigorously with a rough rag, or shake $\mathrm{Hg}$ in a 
bottle, transfer it to a beaker and immerse the bulb.

3. Cold by evaporation. Pour a few drops of ether, alcohol, or carbon bisulphide over the bulb.

4. Endothermic chemical reactions. Add ammonia water to crystals of iodine and immerse the bulb.

5. Exothermic chemical reactions. Immerse the bulb in a beaker of water and add concentrated stilphuric acid.

6. Freezing mixtures. Immerse the buib in snow or chopped ice and afterward add salt.

7. Cooling by solution of a solid. Immerse the bulb in a beaker of water, add potassium nitrate and stir.

8. Heat produced by crystallization. Make a supersaturated solution of alum. When cool immerse the bulb and drop a small crystal of alum in the solution.

9. Cooling produced by the expansion of a gas. Place a rubber cork in the neck of a bell jar and push the top of the tube of the apparatus through the hole of the cork, so that it will have access to the air, while the bulb is in the bell jar. Place on an air pump receiver and rapidly exhaust the air.

Io. Cooling produced by the compression of a gas. After the liquid has come to rest in the above experiment open the valve and allow air to enter the receiver.

II. Water containing ice remains at $o^{\circ} \mathrm{C}$. tuntil all the ice is melted. Place ice and water in a beaker, immerse the bulb and heat, while stirring constantly.

I2. Convection currents in air. Hold the bulb above, below and on the sides of a hot solid.

I3. Conducting power of gases. Place the bulb in a wide mouthed bottle, cork up the opening and inmerse the whole in a larger vessel of hot water.

I4. Conducting power of liquids. Completely immerse the bulb in a beaker of water. Pour a little ether on the water and ignite.

15. Reflection of radiant heat. Reflect the heat rays, emanating from a hot body, from a metallic mirror and place the bulb in the path of the rays.

16. Radiant heat varies inversely as the square of the distance. Place the bulb at different measured distances from a hot body and note the elevation of the liquid column.

I7. Diathermancy and athermancy. Place tanks of alum dissolved in water and of iodine dissolved in carbon bistulphide 
and also sheets of vulcanite, glass, metals, etc., between a source of heat and the bulb.

18. Selective absorption. Place the bulb at the focus of a pencil of light from a projection lantern. But little heating is produced as the rays that would be effective have already been absorbed by the lenses of the lantern and the intervening air. Focus the light on a piece of paper and it will burn. A thin sheet of platinum can thus be heated to redness.

19. Absorption of a blackened body. Blacken the bulb of the thermometer and repeat the above experiment. The thermometer responds at once.

2o. Heating effect of various spectral colors. Hold various colored glass plates in a beam of sunlight or the path of the rays from a lantern. Hold the blackened bulb in the focus of the light.

2r. Heating effect of the electric current. Run an electric current through the wire coil. Regulate the current and note that the heating effect varies as the square of the current.

22. Radiation from a blackened surface. Note how high a certain current will elevate the liquid column "when the bulb is unblackened. Now blacken the bulb and run the same current through the coil. The column will be lower in the last case due to the more rapid radiation of the blackened surface.

23. Specific heat. Place the bulb in a beaker of water. Drop a hot solid into the beaker and read the thermometer. Repeat with other solids of the same weight and temperature as before, always using the same volume of water.

"Kentucky's Mountain Forests" is the general topic to which the September issue of Arboriculture is devoted. It is an excellent issue. Not only are natives trees figured and deseribed, but most commendable results in modern forestry are presented. Kentucky is to be congratulated on the progress made in the decade or less in which the state has given serious attention to forestry.

Teachers of botany who are interested in ferus-and presumably all real teachers of botany are-would do well to miss no numbers of Professor W. N. Clute's "The Fern Bulletin." Written by a most successful student and teacher of the subject, it always contains information and hints that must prove helpful to the readers. Presenting as it does "common knowledge" about ferns, it represents an excellent move toward making botany really accessible to the "common people." 